\title{
Türk Fındığı (Corylus colurna L.)'nın Peyzaj Mimarlığında Kullanım Olanakları
}

\author{
Elif KAYA ŞAHİN ${ }^{1}$, Makbulenur BEKAR ${ }^{1}$, Nilgün GÜNEROĞLU ${ }^{1 *}$ \\ ${ }^{1}$ Karadeniz Teknik Üniversitesi, Orman Fakültesi, Peyzaj Mimarlığı Bölümü, 61080, TRABZON
}

\section{Öz}

Türkiye coğrafi konumu itibariyle ve zengin doğal kaynaklarına bağlı olarak bitki türü çeşitliliği açısından oldukça önemli bir potansiyele sahiptir. Fakat bu bitki türü çeşitliliğinin kentlerde yapılan bitkisel peyzaj tasarımlarında çok fazla değerlendirilmediği görülmektedir. Artan talep ve kolay ulaşım, egzotik türlerin kullanımını oldukça arttırmıştır. Oysa su kaynaklarının azaldığı günümüz koşullarında doğal türlerin kullanımına özen gösterilmelidir. Doğal türlerin, yaşadıkları alanların ekolojik özelliklerine egzotik türlere nispeten daha iyi adapte olduğu unutulmamalıdır. Ayrıca egzotik türlerin kullanımıyla kentlerin kimliklerini bir nebze kaybettiği ve geleneksel yapılarının bozulduğu görülmektedir. $\mathrm{Bu}$ nedenle, bu çalışmada ülkemizin doğal bir türü olan Corylus colurna'nın doğal yayılış alanları, dendrolojik özellikleri, ekolojik istekleri belirlenmiş, işlevsel ve estetik özellikleri araştırılarak bitkisel tasarımlarda kullanım olanakları örneklendirilmek suretiyle anlatılmıştır.

Anahtar Kelimeler: Corylus colurna, Türk findığı, doğal bitki türleri, sürdürülebilirlik.

\section{Usage Opportunities of the Turkish Hazelnut (Corylus colurna L.) in Landscape Architecture}

\begin{abstract}
Turkey has a considerable potential in terms of plant variety depending on its geographical location and rich natural resources. However, it is observed that this variety of plant species is not referred for the urban landscape planting designs. Increased demand and easy access have greatly increased the use of exotic species. However, in today's conditions where water resources are diminished, essential consideration should be given in order to use the natural species. It should not be forgotten that the natural species have adapted to the ecological characteristics of their living spaces better than the exotic species. It is also seen that the use of exotic species has to some extent led to the loss of the urban identities and the traditional structures have deteriorated. For this reason, in this study, the natural distribution areas, dendrological characteristics, ecological requirements of Corylus colurna, which is a natural species of our country have been determined and their functional and aesthetic properties have been investigated and explained referring to the planting application examples.
\end{abstract}

Keywords: Corylus colurna, Turkish hazelnut, natural plant species, sustainability.

\footnotetext{
*Sorumlu Yazar (Corresponding Author):

Nilgün GÜNEROĞLU (Doç. Dr.); Karadeniz Teknik Üniversitesi, Orman Fakültesi,

Peyzaj Mimarlığı Bölümü, 61080, Trabzon-Türkiye. Tel: +90 (462) 377 3587, 


\section{Giriş}

Günümüzde fosil yakıtların kullanımı, endüstrileşme ve yeşil alan kayıpları sera gazlarının atmosferde birikimini arttırmaktadır. Bu artış sera etkisini kuvvetlendirerek küresel iklim değişiklerine neden olmaktadır. Bunun sonucunda dünya üzerindeki ekolojik döngü olumsuz etkilenmekte ve birçok çevresel sorun meydana gelmektedir. Çevre sorunlarının çözümü ve hatta insanların yaşam kalitesinin iyileştirilmesi ve gelecek nesillere daha yaşanılabilir bir dünya bırakmak adına sürdürülebilir peyzaj tasarımları oldukça önem kazanmaktadır. Peyzaj tasarımlarında sürdürülebilirliğin sağlanması için doğanın ve doğal süreçlerin de peyzaj tasarımlarına entegre edilmesi sağlanmalıdır. Sürdürülebilir tasarımların ana amacı kent ekosisteminin içinde kendi kendine yetebilen sistemler oluşturmaktır. Bu sistemlerden, güneşin, rüzgar, 1s1, nem gibi iklimsel özelliklerin tasarımlarda etkin kullanımı, katı ve sıvı atıkların ayrıştırılarak geri kazanımı, güneş enerjisi ile çalışan taşıt ve donatıların kullanımı, verimli toprakların tarım ve kentsel yeşil alan olarak değerlendirilmesi, kişi başına düşen yeşil alan miktarının arttırılması ve mevcut bitki örtüsünün korunması ile doğal türlerin araştırılıp kentsel alanlarda kullanımı sürdürülebilir tasarımların en önemlileri arasındadır (Korkut vd., 2017).

Kent ekosistemleri için oldukça önemli olan açık yeşil alanlar kentlerin ekolojisine katkı sağlamalarının yanısıra kent insanlarına kaliteli yaşam olanakları sunarlar. Kentsel açık alanların en önemli tasarım elemanları bitkilerdir. Hava sıcaklıklarının değiştiği ve su kaynaklarının azaldığı günümüz şartlarında bitkisel materyallerin kentsel alanlarda sürekliliğinin sağlanması oldukça güçleşmiştir. Bu nedenle doğal türlerin bitkisel tasarımlarda kullanımın gerekliliğini konu alan çalışmalar önem kazanmaktadır. Doğal bitkiler bir alanda kendiliğinden yetişebilen, hiçbir insan müdahalesiyle oluşmamış bitkilerdir. Bu bitkiler bulundukları alanların ekolojik koşullarına göre gelişir ve bulundukları alanın diğer bitkileriyle etkileşirler. Bu nedenlerden dolayı doğal bitkilerin doğal olarak yetiştiği alanlara kolay adapte olması kaçınılmazdır. Ayrıca doğal bitkilerin kentlerde kullanımı ile yaban hayatı için gereken habitatlar oluşturularak biyoçeşitliliğin zarar görmesi engellenebilir. Bu sayede, tür çeşitliğinde karşılaşılan kayıplar, bitkiler için gereken bakım masrafları ve bitki adaptasyonu gibi çeşitli olumsuzlukların önüne de geçilebilir. Doğal bitkilerin, bulundukları mekanlardaki tüm çevresel faktörlerle ilişki içerisinde olduğu ve bu faktörlere uyum sağlayabildiği, toprağın verimine katkıda bulundukları ve bitkisel tasarımlarda sürdürülebilirliklerinin daha etkili olduğu bilinmektedir (Deniz ve Şirin, 2005).

Türkiye bulunduğu coğrafi konum, jeolojik ve jeomorfolojik yapı, su kaynakları, farklı toprak yapıları ve iklimsel özellikleri ile zengin bir floristik çeşitliliğe sahiptir. Yaklaşık olarak 12000 bitki türü bulunan ülkemizde 3000'e yakın endemik bitki türü yer almaktadır (Kendir ve Güvenç, 2010). Avrupa kıtasındaki bitki tür sayısına yakın olan bu sayı endemik bitki türü açısından diğer ülkelerden oldukça zengindir (Günal, 2013). Doğal tür açısından oldukça önemli bir kaynağa sahip olan ülkemizde insan baskıları ve koruma önlemlerinin alınmayışı, türlerin azalmasına neden olmaktadır. Günümüzde özellikle kentsel alanlarda doğal türlerin aksine egzotik türlerin tercih edildiği ve oldukça fazla kullanıldı̆̆ı görülmektedir. Egzotik bitkilerin konut bahçelerinden sitelere, parklardan yollara kadar birçok kentsel alanda olduğu gibi köyler, turistik tesisler ve tarımsal alanlar gibi kırsal peyzajda da kullanıldığı belirlenmiştir (Yazgan vd., 2005). Egzotik türlerin bu şekilde kullanım olanağı bulması fidanlıklarda çokça üretimine neden olmakta ve bitkileri temin etmede kolaylık sağlamaktadır. Oysa egzotik bitki türlerinin yayılıcı özelliklere sahip olması nedeni ile doğal bitkileri ve ekolojik dengeyi etkilemesi gibi faktörlerin biyolojik çeşitliliğe zarar verdiği unutulmamalıdır. Bu olumsuz etkiler düşünülerek, doğal bitkilerin kentsel yeşil alanlarda kullanımı yaygınlaştırılmalıdır. Bu kullanımların yapılabilmesi için doğal bitki türlerinin morfolojik ve yetişme ortamı isteklerinin bilinmesi gerekmektedir. Bunların yanı sıra doğal bitkilerin bitkisel tasarımlarda peyzaj değerlerine bağlı kullanım olanaklarının belirlenmesi oldukça önemlidir.

$\mathrm{Bu}$ nedenlerden dolayı çalışmada, ülkemizde doğal olarak yetişen Corylus colurna L.'nin genel özellikleri irdelenerek, peyzaj tasarım ve uygulamalarında yararlanma olanakları ve bitkisel tasarımlarda kullanıma kazandırılması gerekliliği vurgulanmıştır.

\subsection{Corylus colurna L. Ülkemizdeki Doğal Yayılış Alanları}

25 'ten fazla tür ile tanımlanan Corylus, dünya üzerinde mevcut findık türlerinden Adi Fındık (Corylus avellana L.) ve Türk Fındığı (Corylus colurna L.) ülkemizde doğal olarak yetişebilen türler arasındadır. Corylus colurna L. genellikle "kaya findığı”", "ağaç findığı”, “ayı fındı̆̆ı” ve "türk findığı” isimleriyle bilinmektedir. Doğal yayılış alanı güneydoğu Avrupa, Kafkaslar ve İran (Davis, 1982; Yaltırık, 1993; Anşin ve Özkan, 2006; Sezgin vd., 2008) olan Corylus colurna L. yüzyıllar boyu Avrupa ve Amerika'da süs ağacı olarak yetiştirilmiştir (Temel vd., 2017). Ülkemizde ise yayılışı doğuda Gürcistan'dan başlayıp, tüm Karadeniz boyunca uzanıp, Bulgaristan sınırına Istıranca dağları ile uzanır. Türk findığı Kazdağları, Bolu, Kastamonu, Zonguldak, Rize ve 
Trabzon bölgelerinde bulunmakla birlikte (Anşin ve Özkan, 2006), Batı Karadeniz bölgesinde genellikle küçük gruplar halinde Quercus sp., Tilia sp., Fagus sp. gibi bitki türleriyle birlikte karışık şekilde yer almaktadır (Temel vd., 2017). Bunların dışında yapılan literatür çalışmalarında ülkemizde Türk fındığının çok daha geniş bir yayılış alanı olduğu görülmektedir (Sezgin vd., 2008; Polat ve Guney, 2015) (Şekil 1). Ülkemizde nesli tükenme tehlikesi altında olan bu tür için 2008 yılında kesim yasağı getirilmiş ve kesim yapılması yasaklanmıştır.

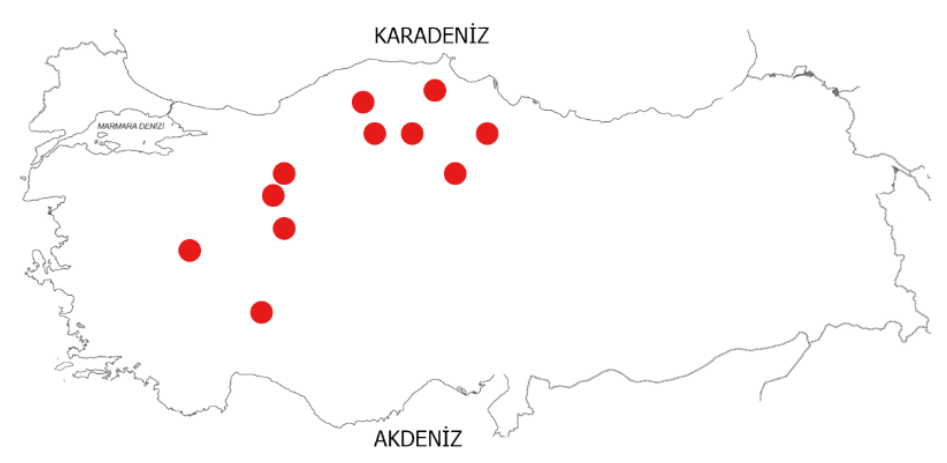

Şekil 1. Türk Fındığg (Corylus colurna L.)’nin ülkemizde yayılış alanları

\subsection{Corylus colurna L. Dendrolojik Özellikleri}

Corylus colurna L., sistematik olarak Betulacea familyasının Corylus cinsi altında yer almaktadır. Ülkemizde doğal olarak yetişen önemli yaprak döken ağaç türlerinden biri olan Türk fındığı, diğer findık türlerimizden farklı olarak tek ve geniş çaplı gövde oluşturması ile belirgin şekilde ayrılmaktadır. Türk findığı doğal yayılış alanlarında 30-35 m boy ve 1,5 m kadar çap yapabilmektedir. Olgunluk döneminde piramit formlu iken, ileriki yaşlarda geniş tepeli bir ağaç siluetine bürünmektedir (Anşin ve Özkan, 2006; Tosun ve Arslan, 2007; Polat, 2014). Çok uzun yıllar yaşayabilen Türk fındığının Bolu'da 400 yıl yaşayan örnekleri anıt ağaç sıfatı ile tescillenmiştir (Pamay, 1992; Polat, 2014). Gövde kabukları Ihlamur ağacı ile benzerlik gösterip, griye yakın renkte beyazdır ve yaşı ilerledikçe derin çatlaklı olmaktadır (Davis, 1982; Pamay,1992; Yaltırık, 1993; Anşin ve Özkan, 2006; Var, 2010). Aynı zamanda Türk fındığının kırmızı renkli, güzel cila tutan, mobilya sektöründe kullanılan değerli odunları vardır. Odunları Orta ve Batı Karadeniz bölgelerinde orman köylüleri tarafından hediyelik eşya imalatında da kullanılmaktadır (Anşin ve Özkan 2006; Polat, 2014).

Hem dikey ve hem de yatay yönde kuvvetli kök yapısına sahiptir (Polatlı ve Güney, 2015). Bu nedenle Türk fındığı, erozyon ile mücadele çalışmalarında da kullanılabilecek önemli türler arasında bulunmaktadır.

Türk findığının çağla yeşili yaprakları geniş oval biçimli, C. avellana'yı andırmaktadır, fakat ondan biraz daha küçük (8-12 cm uzun, 6-8 cm geniş) ve kenarları dişli yapıdadır. Koyu yeşil yapraklarının sonbahar renklenmesi altın sarısı renginde olup oldukça etkili görüntüler oluşturmaktadır. Corylus colurna'nın yaprak sapları 2,5-4 cm uzunluğunda olup, yaprak üzeri yumuşak ve pürüzlü yapışkan tüylüdür.

Şubat-Mart aylarında açan çiçek kurulları $12 \mathrm{~cm}$ uzunluğunda, sarı renkli ve oldukça dikkat çekicidir. Çiçek açtığı dönemde fauna için uygun bir ortam sağlamakta ve özellikle arılar için önemli besin kaynağ oluşturmaktadır. Ağustos ve Eylül ayları arasında olgunlaşan tohum, Eylül-Ekim aylarında toplanmaktadır. Meyvelerinin şekilleri yuvarlak, dip tarafı sivri şekildedir ve meyveyi diştan saran kabuklar ince-dar şeritler halinde saçaklıdır (Pamay,1992) (Şekil 2). 

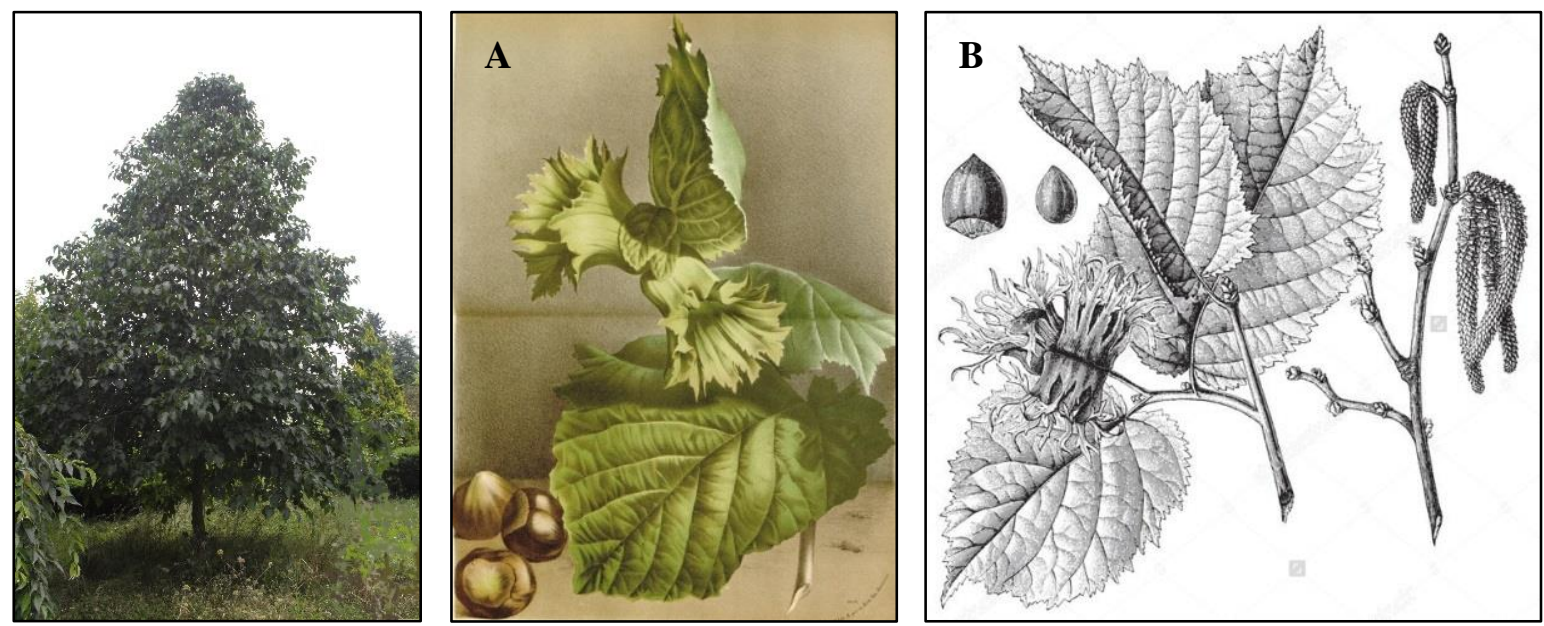

Şekil 2. Türk fındığının habitüs, yaprak, çiçek ve meyvesi (Resim A: URL-1, Resim B: URL-2)

Türk fındığının meyveleri hem yaban hayatı ve hem de insanlar için değerli bir besin kaynağıdır. Meyveler bazı yörelerde doğrudan tüketilmektedir. Bolu'da ise findık şekeri ve çikolata imalatında kullanılmaktadır. Diğer fındık meyvelerine kıyasla, çok kalın kabukludur. Meyvenin meyve örtüsüne bağlandığı mat kısım findığın hemen hemen yarısına kadar gelmektedir, ki bu özellik Türk fındığı için ayırt edici karakteristik bir özelliktir (Yaltırık, 2000; Arslan, 2009; Polat, 2014). Meyvelerinde oleik asit, linoleik asit ve diğer pek çok faydalı maddeler bulunmaktadır. Bu maddelerin kalp hastalı̆̆ı, ikinci tip şeker hastalığı, çeşitli (prostat, meme) kanser vakaları, obezite ve iltihaplı eklem romatizması gibi hastalıkların önlenmesinde etkili olduğu belirtilmektedir (Çelik ve Demirel, 2004; Erdoğan ve Aygün, 2005; Arslan, 2006).

\subsection{Corylus colurna L. Ekolojik Ístekleri}

Corylus colurna L. toprak isteği bakımında nemli-taze, derin toprakları tercih etmektedir. Kurakçıl alanlarda ve humuslu topraklarda gelişmekle birlikte balçıklı, fazla miktarda alkalileşen topraklara bile dayanıklılık göstermektedir (Pamay, 1992). Kuraklığa olduğu gibi özellikle kış şartlarına dayanıklılığı oldukça yüksektir. Hatta $-5^{\circ} \mathrm{C},-30^{\circ} \mathrm{C}$ gibi sicaklık değerlerinde bile yaşamını sürdürebilir. Kazık köklere sahip olduğu için fırtınaya, kar kırmalarına, taşkın ve sel şartlarına karşı dayanıklıdır (Pamay,1992; Arslan, 2005; Tosun, 2012, Polat, 2014). Nem isteği fazla olan bu bitkinin ülkemizde genel olarak Karadeniz ikliminin hâkim olduğu yörelerde 800-1700 m yükseltileri arasında yayılış gösterdiği görülmektedir. Türk findığı, zararlı gaz emisyonlarına karşı dayanıklığı, yetişme ortamı isteği bakımından kanaatkâr oluşu ve bunun yanında sunmuş olduğu estetik görünüş itibariyle yurt dışındaki peyzaj çalışmalarında yaygın şekilde tercih edilen bir süs ağacıdır (Pamay,1992; Arslan, 2005; Tosun, 2012; Polat, 2014; Polatlı ve Güney, 2015).

\subsection{Corylus colurna L. Peyzajda Kullanım Alanlart}

Türk findığı kentsel alanlarda gerçekleştirilen peyzaj planlama projelerinde, sahip oldukları birçok özellikleri sayesinde yaygın kullanım potansiyeline sahip bir bitkidir. Özellikle tek gövdeli yaprak yüzeyinin geniş ve kaba dokulu olmasının yanı sıra sunduğu gösterişli görünümü, estetik özellikleri açısından çok dikkat çekicidir. Kentlerde endüstri ve egzoz gazlarıyla meydana gelen kirliliğe karşı oldukça dayanıklıdır. Kuraklığa dayanıklı bir bitki oluşu sayesinde, su kıtlığının sorun olduğu ve kentsel 1sı adası etkisinin gözlemlendiği kentlerde Türk fındığının kullanım olanakları artmaktadır. Bu nedenlerle kentsel alanlarda soliter veya grup bitkisi olarak yollar, bahçeler ve parklarda değerlendirilebilirler (Şekil 3). Ayrıca budama isteğinin minimum düzeyde olması, böcek ve mantar gibi herhangi bir bitki zararlısının bulunmayışı gibi imkanları kentsel alanlarda bitki için harcanan bakım masraflarını azaltarak ülke ve kent ekonomisine olumlu katkı sağlayabilmektedir. Ayrıca canlılar için yaşam alanı oluşturması ve besin sağlaması kentsel alanlardaki fauna için oldukça önemlidir (Tosun, 2012).

Alle ağacı olarak kullanıldıklarında cadde ve sokaklarda etkili görünümler oluşturmalarının yanısıra, gündüz güneş ışınlarını, gece ise sokak aydınlatmalarından kaynaklanan 1şık olumsuzluklarını azaltabilektedirler. Gece araçların far 1şıklarıyla oluşan etkileri azaltarak, yayaların ve diğer araç kullanıcılarının güvenliğini arttırırlar. Bunların dışında bitkisel tasarımlarda bitkilerle yapılan perdelemelerde kullanılan türler arasında tercih edilebilirler (Şekil 4). 


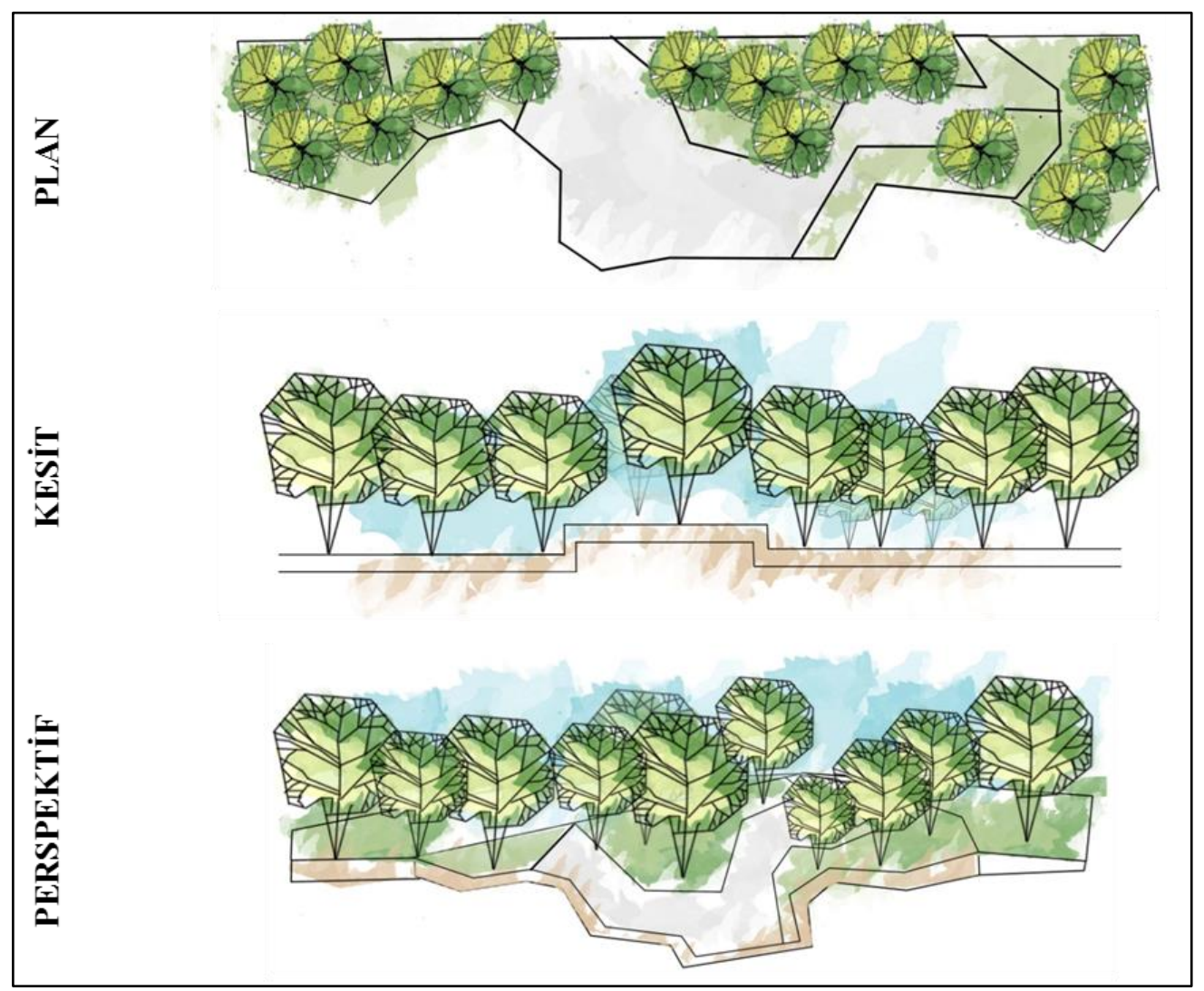

Şekil 3. Türk fındığının grup kullanımı

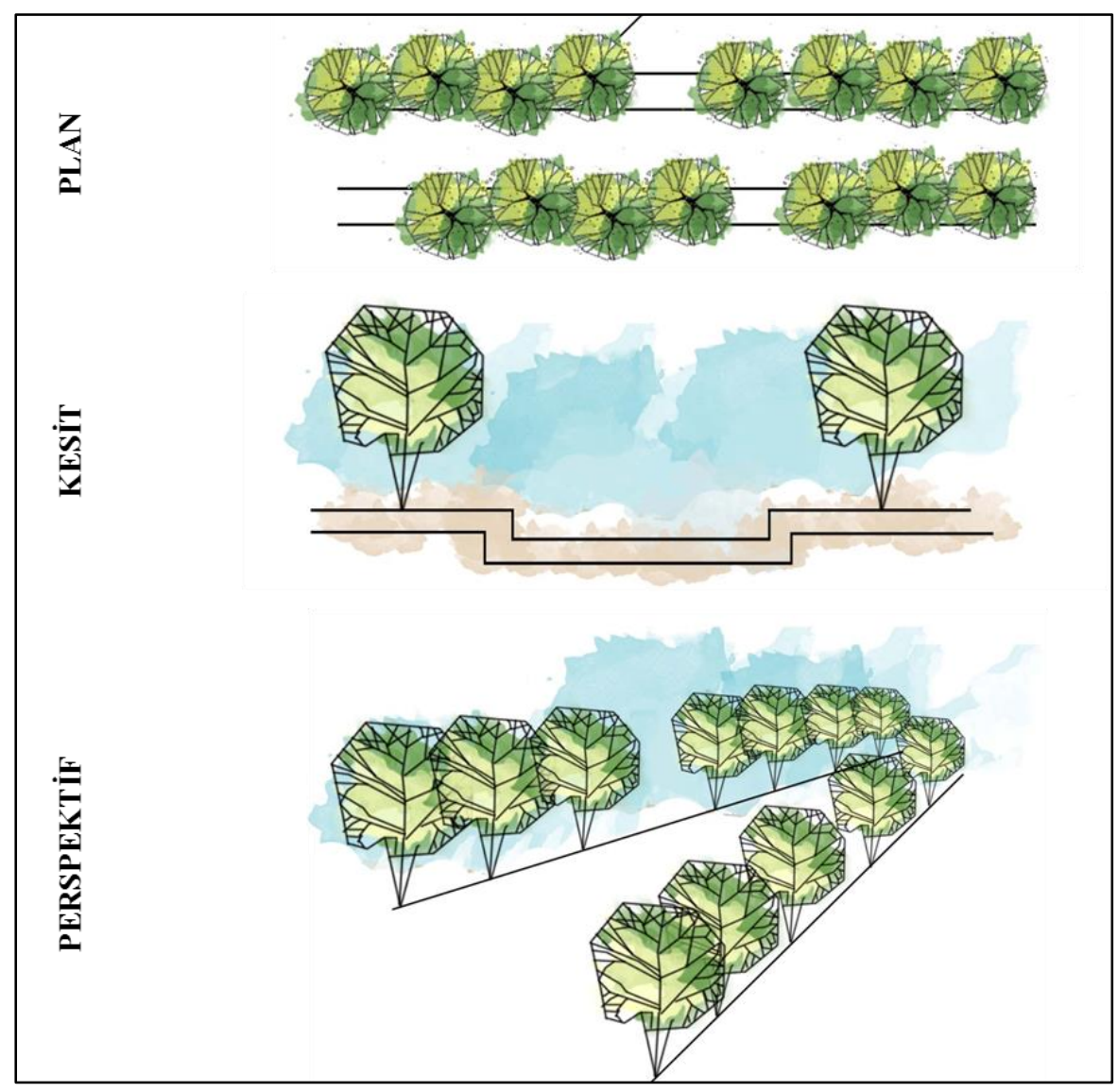

Şekil 4. Türk findığının yol ağacı olarak kullanımı 
Erken ilkbaharda açan tilkikuyruğu görünümlü erkek çiçek kurulları da diğer estetik özellikleri arasındadır. Mevsimsel değişikliklerde sunduğu güzel avantajlarının bir tanesi de, sonbaharda yapraklarının sarıya dönüp çok güzel perspektifler oluşturmaya yatkın oluşudur. Ayrıca bitkinin yapraksız yapısıyla sunduğu kaligrafik özelliği de oldukça dikkat çekicidir. Açık yeşil, oval yapraklara sahip olan Corylus colurna ile koyu yeşil yapraklı kaba tekstürlü bitki türleri ile bir arada kompozisyonlar oluşturulduğunda, yaz yeşili yaprak rengi sayesinde güzel görüntüler ortaya çıkmaktadır. Ayrıca ihtişamlı görüntüye sahip olduğundan dolayı, soliter olarak tercih edildiğinde oldukça etkili bir görüntü sergiler ve nitekim bitkilendirme tasarımlarında müthiş bir vurgu etkisi yaratır (Şekil 5).

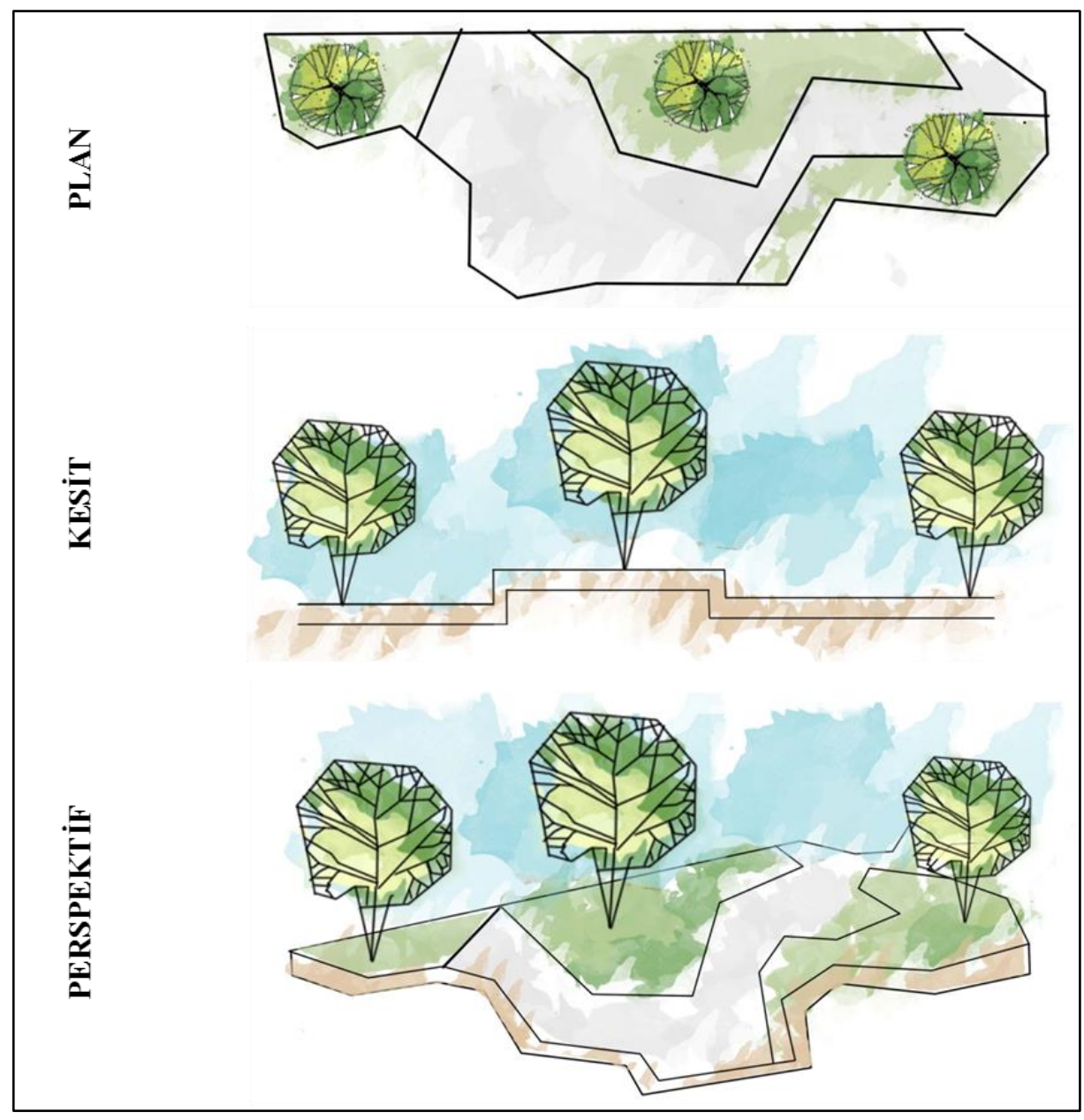

Şekil 5. Türk Fındığının soliter kullanımı

Dikey ve yatay yönde bulunan kökleri nedeniyle erozyon kontrolü, şev stabilizasyonu ve rüzgar perdesi tasarımlarında kullanılan bitkiler arasındadır (Şekil 6). Ayrıca fırtına ve kar kırılmalarına karşı oldukça dirençli bir bitki olması da tercih edilmelerindeki en önemli özellikler arasındadır.

Sahip olduğu özellikleri ile kentsel peyzaj tasarımlarında olduğu gibi kırsal peyzaj tasarımlarında da kullanılabilecek önemli bitkiler arasındadır. Özellikle tarım alanlarında ıhlamur, kestane, kızıl ağaç türlerine alternatif olarak kullanılabilecek bir bitkidir. Bu bitkiler, kırsal kesimde bulunan halkın, tarımsal ürünlerin yanı sıra kullandıkları bitkilerden de faydanma imkanı sunarlar. Örneğin ıhlamurun, tarım alanında biyolojik çeşitliliğe katkı sağlamasına ek olarak, çiçeklerinin şifalı oluşu, odununun yakacak olabilmesi ve mobilyacılıkta kullanılabilmesi ve yapraklarının hayvan yemi olarak kullanılması gibi olanaklar sunması ile kırsal nüfusa birçok yarar sağlamaktadır. Türk fındığı da değerli odunu, yenilebilir meyveleri ve kanaatkar yetişme şartları gibi özellikleri ile tarımsal peyzajlarda da değerlendirilmektedir. Özellikle verim gücü düşük tarım arazilerinin ağaçlandırılmasında uygun bir bitki türüdür (Palzaoğlu vd., 2013). Ayrıca karayolu şev stabilizasyonu gibi sorunlu alanlarda yapılan peyzaj onarımı çalışmalarında da kullanılabilir. 

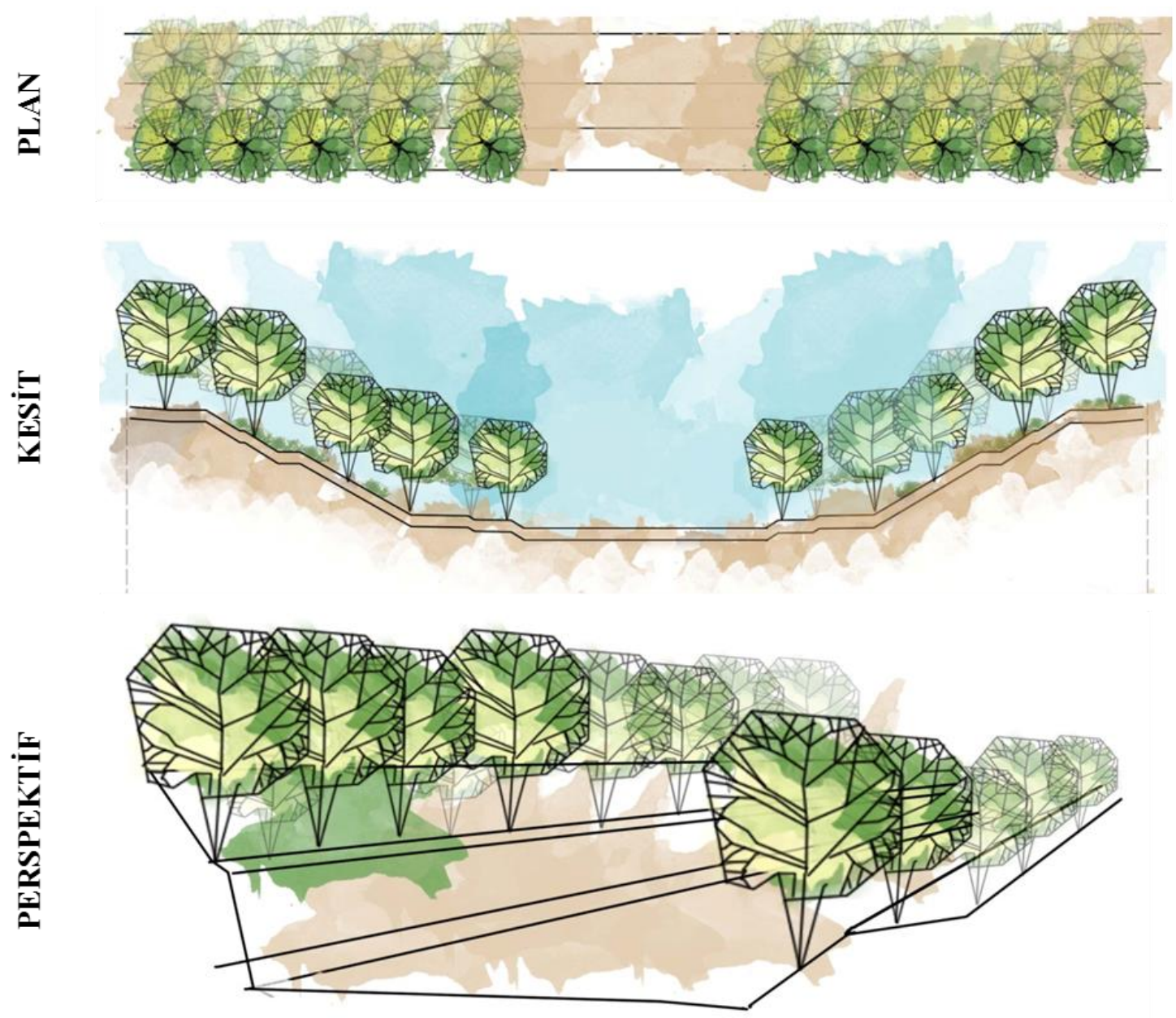

Şeki 6. Türk findığının şev stabilizasyonlarında kullanımı

\section{Sonuç ve Öneriler}

Türkiye bulunduğu coğrafik konum itibari ile zengin doğal bitki türü çeşitliliğine sahiptir. Fakat doğal bitkilerin hem kentsel hemde kırsal peyzaj tasarımlarında çok fazla etkin bir şekilde kullanılmadığı görülmektedir. Günümüzde ise artan yapılaşma ve azalan yeşil alanlar, peyzaj tasarımlarının sürdürülebilirlik kavramına göre şekillenmesine neden olmuştur. Özellikle ekolojik, estetik ve fonksiyonel açıdan sürdürülebilir tasarımlarda doğal bitkilerin kullanıma önem verilmektedir. Bu noktada, doğal bitkilerin doğal olarak yaşayabildikleri alanlarda kullanımları ile en ideal sürdürülebilir tasarımların oluşturulacağı açıktır.

Yapılan bu çalışmada ele alınan Corylus colurna'nın doğal bitki türü olmasının yanı sıra kanaatkâr, dayanıklı olması, değerli meyve özelliği ve estetik görüntüsü gibi birçok farklı özelliğinin olduğu vurgulanmıştır. Bu bitki ülkemizin doğal türü olmasına rağmen Avrupa ve Amerika'da kentsel peyzaj tasarımlarında oldukça yaygın olarak kullanılmaktadır. Ülkemizde ise yapılan peyzaj tasarımlarında Corylus colurna gibi doğal bitkilerin yerine egzotik türlerin kullanımının yaygın olduğu göze çarpmaktadır. Oysa Türk fındığının ülkemizde gerçekleştirilen peyzaj tasarımlarında kullanımın yaygınlaştırılması sağlanmalıdır. Bu kullanımlarla peyzaj tasarımları estetik ve fonksiyonel olarak zenginleşeceği gibi ülkemize ekonomik olarak geri dönüşler sağlanmış olacaktır. Ayrıca muhtemel küresel ısınma ve sonucunda ortaya çıkabilecek kuraklık gibi olumsuzluklar için ideal kullanımlar sunacaktır.

\section{Kaynaklar}

1. Anşin R. ve Özkan Z. C. (2006). Tohumlu Bitkiler (Spermatophyta), Odunsu Taksonlar, KTÜ Genel Yayın No: 167, Orman Fak. Yayın No: 19. KTÜ Basımevi. Trabzon. 
2. Arslan, M. (2005). Batı Karadeniz Bölgesindeki Türk Fındığı (Corylus colurna L.) Populasyonlarının Ekolojik ve Silvikültürel Yönden İncelenmesi. Yüksek Lisans Tezi, Abant İzzet Baysal Üniversitesi, Fen Bilimleri Enstitüsü, Bolu.

3. Arslan, M. (2006). Geçmişle Paylaştığımız ve Geleceğe Miras Bırakmamız Gereken Doğal Türlerimizden Türk Fındığı (Corylus colurna L.). 1.Uluslararası Odun Dışı Orman Ürünleri Sempozyumu-Bildiriler Kitabı, 302-310, 1-4 Kasım 2006, Trabzon.

4. Arslan, M. (2009). Kabukları çıkartılmış türk findığı tohumlarına uygulanan ön işlemlerin çimlenmeye etkisi, Ormancılık Dergisi, Cilt:5, Sayı: 1.

5. Çelik, S. ve Demirel, M. (2004). İnsan ve hayvan sağlığı bakımından omega yağ asitleri ve konjuge linoleik asitin önemi. YY Ü. Fen Bilimleri Enstitüsü Dergisi, 1, 25-35.

6. Davis, P. H. 1982. Flora of Turkey and The East Aegean Islands, Edinburg University Press, Edinburg.

7. Deniz, B. ve Şirin, U. (2005). Samson dağı doğal bitki örtüsünün otsu karakterdeki bazı örneklerinden peyzaj mimarlığı uygulamalarında yararlanma olanaklarının irdelenmesi. Adnan Menderes Üniversitesi Ziraat Fakültesi Dergisi, 2(2), 5-12.

8. Erdoğan, V. ve Aygün, A. (2005). Fatty acid composition and physical properties of Turkish tree hazelnuts, Chemistry of Natural Compounds, 41(4): 378-381.

9. Günal, N. (2013. Türkiye'de iklimin doğal bitki örtüsü üzerindeki etkileri. Acta Turcıca Çevrimiçi Tematik Türkoloji Dergisi, Online Thematic Journal of Turkic Studies, Y1l V, (1).

10. Kendir, G., ve Güvenç, A. (2010). Etnobotanik ve Türkiye'de yapılmış etnobotanik çalışmalara genel bir bakış. Hacettepe Üniversitesi Eczacılık Fakültesi Dergisi, 30(1), 49-80.

11. Korkut, A., Kiper, T., ve Topal, T. Ü. (2017). Kentsel peyzaj tasarımda ekolojik yaklaşımlar.Artium, $5(1) ; 14-26$.

12. Palzaoğlu, Z.Ö., Arslan, M. ve Tosun, S. (2013). Batı Karadeniz Bölgesi’nde Türk Fındığı (Corylus Colurna L.)'nın Ex-Situ Yöntemiyle Korunmaya Alınması ve Populasyonlarda Genetik Çeşıtliliğin Araştırılması, Batı Karadeniz Ormancılık Araştırma Enstitüsü Müdürlüğü, Teknik Bülten No:18, Bolu.

13. Pamay, B. (1992). Bitki Materyali 1. Ağaç ve Ağaçcıklar Bölümü, Uycan Matbaası. İstanbul.

14. Polat, S. (2014). Türk Fındığı (Corylus colurna)'nın Türkiye'deki yeni bir yayılış alanı, Marmara Coğrafya Dergisi, S. 29, s. 136-149.

15. Polat, S. ve Güney, Y. (2015). Türk Fındı̆̆ı'nın (Corylus Colurna) Türkiye'deki yeni bir yayılış alanı, Akademik Sosyal Araştırmalar Dergisi, Y11: 3, Sayı: 18, 449-460.

16. Temel, F., Arslan, M. ve Çakar, D. (2017). Status of natural Turkish hazel (Corylus colurna L.) populations in Turkey. Artvin Coruh University Journal of Forestry Faculty, 18(1);1-9.

17. Tosun, S. ve Arslan, M. (2007). Göreni şaşırtan görkemli türk findığı, Çevre ve İnsan Dergisi. 2, 69.

18. Tosun, S. (2012). Cadde (Yol) Ağacı olarak Amerika'da ve Avrupa'da popülerleşen türk findığı (Corylus colurna L.). Orman ve Av Dergisi, S.3, 22-25.

19. Var, M. (2010). Bitki Tanıma ve Değerlendirme II Ders Notları, Trabzon. (Basılmamış)

20. Yaltırık, F. (1993). Dendroloji Ders Kitabı 2. Angiospermae. Bölüm-1. İ.Ü. Orman Fakültesi Yayınları No. 3767/420.Matbaa Teknisyenleri Koll.Şti. İstanbul.

21. Yaltırık, F. (2000). Dendroloji Ders Kitab1 Gymnospermae-Angiospermae. (Orman Endüstrisi Mühendisliği Bölümü Öğrencileri İçin), İstanbul Üniversitesi Orman Fakültesi Yayınları, İstanbul. 
22. Yazgan, M. E., Korkut, A. B., Barış, E., Erkal, S., Yılmaz, R., Erken, K., Gürsan, K. ve Özyavuz, M. (2005). Süs bitkileri üretiminde gelişmeler. Ziraat Mühendisleri Odası Teknik Kongresi, 3-7.

23. URL 1 (2019). http://hortuscamden.com/plants/view/corylus-colurna-1 (20/10/2019).

24. URL-2 (2019). https://www.shutterstock.com/tr/image-vector/turkish-hazel-corylus-colurna-vintageillustration-93544153 (20/10/2019). 